International Review of Research in Open and Distributed Learning Volume 22, Number 2

May - 2021

\title{
Editorial - Volume 22 Issue 2
}

Constance Blomgren

Associate Editor, Athabasca University

Welcome to this issue of IRRODL. Our authors, reviewers, and editors have all been busy working to bring you the following contributions. We have 13 research articles, two book reviews, and three substantial literature reviews.

"Investigation of Emerging Trends in the E-Learning Field Using Latent Dirichlet Allocation" by Fatih Gurcan, Ozcan Ozyurt, and Nergiz Ercil Cagitay applied text mining to determine topic modeling and trends in the e-learning field.

Aras Bozkurt and Olaf Zawacki-Richter authored "Trends and Patterns in Distance Education (20142019): A Synthesis of Scholarly Publications and a Visualization of the Intellectual Landscape." Using social network analysis and text mining Bozkurt and Zawacki-Richter analyzed the changes in distance education scholarship ending with future research suggestions.

Florence Martin, Doris U. Bolliger, and Claudia Flowers developed and validated an online course design element instrument and report their findings in "Design Matters: Development and Validation of the Online Course Design Elements (OCDE) Instrument."

Adding to the scholarship of OER, Angela R. Hillman, Anna R. Brooks, Marcus Barr, and Jesse Strycker report their findings of "Evaluation of Open Educational Resources for an Introductory Exercise Science Course."

"Impact of Changes in Teaching Methods During the COVID-19 Pandemic: The Effect of Integrative ELearning on Readiness for Change and Interest in Learning Among Indonesian University Students" is authored by Anggun Resdasari Prasetyo, Harlina Nurtjahjanti, and Lusi Nur Ardhiani. They report on the effectiveness of an integrative e-learning method examining scales for readiness for change and interest in learning.

George Veletsianos, Charlene A. VanLeeuwen, Olga Belikov, and Nicole Johnson provide a qualitative study of digital education in their article, "An Analysis of Digital Education in Canada in 20172019."

"Ready to Do OpenCourseWare? A Comparative Study of Taiwan College Faculty" is a study completed by Huei-Chuan Wei and Chien Chou. They examine teaching readiness of open courseware with respect to experience and factors of perception including administrative support, personal characteristics, and OCW recognition. 
Hanife Çivril and Ali Ekrem Özkul examine virtual laboratories as part of open learning and apply the technology acceptance model to their mixed methods study, "Investigation of the Factors Affecting Open and Distance Education Learners' Intentions to Use a Virtual Laboratory.”

"IDEAS for Transforming Higher Education: An Overview of Ongoing Trends and Challenges" is an exploratory three-part study. Lourdes Guàrdia, Derek Clougher, Terry Anderson, and Marcelo Maina examine technological, organizational, and pedagogical higher education trends and challenges to formulate the IDEAS framework for transformational next-generation pedagogy.

"What Is Open Pedagogy? Identifying Commonalities" examines the literature of open pedagogy and proposes a five-part framework. Phil Tietjen and Tutaleni I. Asino argue for a robust analytical framework to further research of open pedagogy.

Ermira Idrizi, Sonja Filiposka, and Vladimir Trajkovijk contributed their study, "Analysis of Success Indicators in Online Learning." They conducted a case study to determine significant factors of academic performance of students taking online courses.

"Parents' Perceptions of Their Children's Experiences With Distance Learning During the COVID-19 Pandemic" provides research that is very timely for understanding young online learners. Diala Hamaidi, Yousef Arouri, Rana Noufal, and Islam Aldrou conducted a study in Jordan that provides the parental perspective on online learning for children.

Megan Ennes reports on her study, "Museum-Based Distance Learning Programs: Current Practices and Future Research Opportunities.” Again, due to the global pandemic, museum-based distance learning programs have become a timely area of research.

Our first book review is by İrem Demirbağ and Sedef Sezgin and they provide their take on Guidelines on the Development of Open Educational Resources Policies. Özlem Oktay and Firat Sösuncu examine the book, Learning Online-The Student Experience.

We have three literature reviews with the first, "Mentoring Graduate Students Online: Strategies and Challenges," authored by Rhiannon Pollard and Swapna Kumar. The second offering, "A Systematic Review of Questionnaire-Based Quantitative Research on MOOCs," is by Mingxiao Lu, Tianyi Cui, Zhenyu Huang, Hong Zhao, Tao Li, and Kai Wang. The final literature review by Jewoong Moon and Yujin Park provides "A Scoping Review on Open Educational Resources to Support Interactions of Learners with Disabilities."

Best wishes and enjoy this issue.

\section{Athabasca}

University

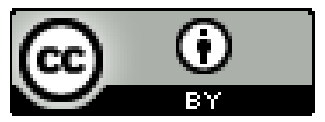

